\title{
ENSINO E APRENDIZAGEM MUSICAIS NA ESCOLA PRODUZINDO SUBJETIVIDADES
}

\author{
Lucielle Farias Arantes \\ Universidade Federal de Uberlândia \\ luciellearantes@ufu.br
}

\section{Introdução}

Este texto tem o objetivo de apresentar a Teoria da Subjetividade, desenvolvida pelo psicólogo cubano González Rey na perspectiva Histórico-Cultural, e o conceito de aprendizagem criativa, cunhado pela psicóloga cubana Mitjáns Martínez a partir da teorização sobre a temática da subjetividade, como aportes relevantes à Educação Musical, sobretudo tendo-se em vista a elaboração de propostas para o ensino e a aprendizagem musicais na escola de educação básica. Tais postulados têm lugar na pesquisa de doutorado em andamento que visa desenvolver princípios de uma didática desenvolvimental da subjetividade para o ensino de Música na escola.

Segundo a Teoria Histórico-Cultural, fundada a partir das elaborações do psicólogo bielorusso Lev Semenovitch Vigotsky (1896-1934), a educação cumpre a um papel extremamente importante por viabilizar a apropriação pelos indivíduos do patrimônio cultural produzido historicamente pela humanidade, com o que desenvolvem seu conhecimento e suas capacidades propriamente humanas. Fundamentada no marxismo, no ensejo de formar o novo homem para a sociedade socialista que se constituía na União Soviética pós-revolução, a Psicologia constituiu a base dos pressupostos pedagógicos, destacando-se a produção de Vigotsky e de seus seguidores, dentre eles A. N Leontiev, fundador da Teoria da Atividade.

A concepção didática forjada na tradição marxista sobre a base da Teoria da Atividade apresentou importantes contribuições ao campo educacional, mas ao seguir a uma leitura ortodoxa do materialismo, pouco dialético, encontrou seus limites. É que ao se compreenderem os fenômenos psíquicos como decorrentes da atividade externa, objetal, incorreu-se no subjulgamento da capacidade geradora da psique e na primazia do desenvolvimento dos processos do pensamento como se fossem 
reflexos do meio externo e passível de realização dissociada dos processos afetivoemocionais. Dessa forma, os processos de ensino e aprendizagem foram centralizados no desenvolvimento da dimensão cognitiva, ao passo em que o desenvolvimento da dimensão afetivo-emocional do humano era entendido como sua consequência e, assim, secundário no processo educacional.

Ter em vista o desenvolvimento integral dos sujeitos requer o entendimento de que o ensino deve ter em conta não só os aspectos de ordem cognitiva, com o desenvolvimento da capacidade de resolução de problemas e da construção de conhecimentos, mas também os aspectos de cunho afetivo-emocional gerados na psique, com o desenvolvimento da imaginação e da fantasia, da criatividade, dos afetos e das emoções em uma unidade indivisível com o pensamento.

Uma didática voltada ao desenvolvimento humano, partindo-se do pressuposto de que ele é gerado pelo ensino, conforme definido na Teoria HistóricoCultural, e que se efetive sobre a base da subjetividade, em reconhecimento da unidade simbólico-emocional, está por ser elaborada. Nessa seara, a Teoria da Subjetividade e o conceito de aprendizagem criativa abrem zonas de inteligibilidade, inclusive no que tange ao ensino e aprendizagem de Música em contexto escolar, levando em consideração os processos de ordem simbólico-emocional que conferem a singularidade aos caminhos e sentidos produzidos por cada sujeito em particular ao lidar com o objeto musical.

\section{Subjetivando experiências}

Na perspectiva de González Rey (2005, 2012b), como indivíduo produtivo o sujeito constitui e desenvolve sua subjetividade em sua ação desferida no momento atual de sua existência social, que, por sua vez, é implicada com sua história de vida, com suas experiências passadas. Isso significa que a dimensão intrapsíquica do humano se configura a partir da atividade subjetivada, sob a forma de sentidos subjetivos quando o sujeito, em ação em seus distintos cenários, constitui processos simbólico-emocionais partilhando ideias, tradições, discursos, representações, valores. Na permanente relação entre os sentidos produzidos na ação e aqueles relativamente estáveis, configurados em experiências anteriores, o sujeito produz sua 
subjetividade, desenvolvendo sua personalidade e provocando modificações nos contextos de suas práticas sociais.

Para além dos elementos objetivos que afetam o humano, González Rey defende a existência de uma realidade subjetiva que implica simultaneamente o humano e a subjetividade dos espaços sociais dos quais toma parte, integrando o histórico e o atual, bem como o individual e o social no plano subjetivo. De tal modo, pode se dizer que o sujeito é singular, mas é também social.

A subjetividade trata-se, pois, de um sistema em desenvolvimento, em que se produzem e organizam processos simbólicos em unidade indissociável com os emocionais. Essa unidade, definida como "sentido subjetivo", caracteriza-se por expressar-se na ação, nas diversas manifestações do sujeito, e, embora os processos da ordem simbólica e emocional emirjam uns na presença dos outros, não se pode afirmar que uns são causas dos outros. Segundo González Rey, a crença de que emoções são consequências de significados remete ao racionalismo dominante na psicologia ocidental. Para ele, a emoção se associa aos registros simbólicos e a partir dessa integração se dá a organização de um sistema psíquico qualitativamente diferenciado (GONZÁLEZ REY, 2005: 38).

À ótica da Teoria da Subjetividade, personalidade passa a ser compreendida como uma organização subjetiva que nunca se expressa perfeitamente definida, estável e acabada, apesar da relativa estabilidade que caracteriza a constituição subjetiva gerada na experiência concreta do sujeito. A personalidade é, pois, o sistema da subjetividade individual, sendo esta constituída dialeticamente na relação com a subjetividade social. Essa relação se faz na tensão permanente entre o indivíduo e os processos institucionalizados de sua vida social, em que uma dimensão subjetiva constitui a outra de modo singular, tanto nos espaços sociais quanto nas pessoas ao compartilhar suas práticas em tais espaços. Embora as subjetividades individual e social sejam, de certa maneira, independentes uma da outra, uma se configura na outra.

A Teoria da Subjetividade implica o campo educacional colocando o aluno no centro dos processos de ensino e aprendizagem como "sujeito que aprende" e se desenvolve. A aprendizagem passa a ser concebida a partir da produção de sentidos subjetivos, sentidos esses configurados pelo aluno na ação, no contexto da sala de 
aula em uma relação dialética com as configurações subjetivas constituídas e reconstituídas em situações e momentos diversos, sejam na escola e ou em outros espaços e contextos, organizadas em sua subjetividade individual (GONZÁLEZ REY, 2012a).

\section{Emocionalidade e imaginação na base de aprendizagens complexas}

A concepção do ensino fundamentado na Teoria da Subjetividade demanda abordagens comprometidas com a expressão do aluno que, na condição de "sujeito que aprende", o faz por produzir sentidos, entremeando emoções às significações da ordem do simbólico.

Considerando especificamente a produção de sentidos face à aprendizagem musical, Souza (2015) observa que, embora a dimensão emocional seja fortemente associada às práticas musicais, suas implicações ao ensino e aprendizagem raramente são problematizadas. Há antes, tanto em pesquisas quanto no trabalho docente, a valorização do conhecimento musical enquanto conteúdo específico a ser transmitido e dos procedimentos para sua transmissão, do que o tratamento do papel das emoções nos processos de ensino e aprendizagem, com suas consequências nas configurações subjetivas das pessoas.

Assim como ocorre com a dimensão emocional, Mitjáns Martínez (2014) salienta que a imaginação e a fantasia nem sempre são promovidas de forma intencional, com vistas à promoção de novos níveis de desenvolvimento, enfocandose mais o potencial lúdico desses fenômenos subjetivos, sobretudo considerando as atividades voltadas às crianças da educação infantil e em processos de expressão artística. A autora analisa que, de forma geral, nas disciplinas escolares do ensino fundamental a imaginação deixa de ser valorizada, passando a ser vista até mesmo como empecilho aos processos de aprendizagem, o que se explica pela perspectiva do ensino como transmissão de saberes pelo professor e a assimilação do conhecimento pelo aluno. Nesse contexto, Mitjáns Martínez ressalta que mesmo em processos influenciados pelo paradigma construtivista, "o caráter ativo está orientado para a assimilação do dado e não para a produção personalizada, para a geração de ideias próprias, que podem chegar a transcender o dado, movimento no qual a imaginação se expressa em todas suas possibilidades" (MITJÁNS MARTÍNEZ, 2014: 
69). Além disso, a representação do conhecimento como algo acabado, intimida a produção de processos imaginativos e a emersão de novas ideias dos alunos.

No que tange ao lugar atribuído à imaginação na aprendizagem escolar, Mitjáns Martínez (MITJÁNS MARTíNEZ, 2014: 78-84) considera três categorias que, dependendo do contexto, podem se articular. A primeira categoria refere-se à "imaginação como ferramenta para transcender à experiência vivida". Nesse caso, a imaginação possibilita ao aluno a representação de experiências que não viveu, construindo relações entre conteúdos estudados e conhecimentos. A segunda categoria considera a "imaginação como elemento constitutivo dos processos de compreensão". Essa categoria tem a ver com a produção intencional de imagens e metáforas, dentre outros recursos, dos quais o aluno lança mão no intento de superar obstáculos na compreensão de novos conteúdos. A terceira categoria, por sua vez, diz respeito à "imaginação como elemento essencial na produção de novos conhecimentos", estando muito relacionada aos processos de aprendizagem criativa. Nesse lugar, a imaginação se apresenta como ideias próprias do sujeito transcendendo modelos, teorias e modos de ver o mundo. Com papel primordial à produção de novos conhecimentos, proporciona a emersão de respostas diante os limites do conhecimento. Segundo a autora, é possível que os sujeitos que aprendem valendo-se da imaginação conforme esta categoria, além de integrarem-na às configurações subjetivas da aprendizagem, têm a amplitude de seu funcionamento subjetivo caracterizado por esse tipo de produção, marcando suas configurações subjetivas da personalidade.

Em seus estudos Mitjáns Martínez se atenta às duas distintas e complexas formas de aprendizagem escolar que, diferentemente de centrarem-se nas formas de reprodução de conteúdos, favorecem o desenvolvimento do aprendiz no sentido da sua produção subjetiva. São elas a aprendizagem compreensiva e a aprendizagem criativa. Na primeira, o aprendiz se implica no processo de aprendizagem como sujeito ativo, envolvido emocionalmente. Seus esforços são voltados a compreender os elementos que constituem a essência do objeto do conhecimento. Nesse intento, ele atua com seu caráter gerador na medida em que reestrutura conhecimentos, personalizando informações. A autora esclarece que "no processo de aprender compreensivamente, atualizam-se configurações subjetivas constituídas na história 
de vida do aprendiz e se configuram novos sentidos subjetivos gerados na própria ação de aprender" (MITJÁNS MARTÍNEZ, 2014: 75, grifo da autora). Já a aprendizagem criativa requer a articulação de três elementos: "personalização da informação, confrontação com o dado e transgressão, geração de ideias próprias que vão além do dado". Embora tanto na aprendizagem compreensiva quanto na criativa haja a produção de ideias próprias, é na aprendizagem do segundo tipo que se transcende ao dado a partir do confronto com o objeto de conhecimento. Esta é uma forma de aprendizagem considerada rara no contexto escolar devido à sua complexidade constitutiva, articulando-se "recursos subjetivos, que se constituem ao longo da vida do aprendiz, a partir de sistemas sociorrelacionais que não tipificam o cenário escolar atual" (MITJÁNS MARTíNEZ, 2014: 76). Trata-se de um modo diferenciado de aprender que, além de superar a aprendizagem como reprodução, tem o subjetivo com toda sua potência em posição de destaque. Assim, sua promoção se faz altamente desejável em contextos educacionais que se querem comprometidos com os processos da subjetividade.

A concepção de criatividade que subjaz a aprendizagem do tipo criativa, conforme cunhada por Mitjáns Martínez, teve seu desenvolvimento concomitante à Teoria da Subjetividade, sendo conceituada como: "um processo complexo da subjetividade humana na sua simultânea condição de subjetividade individual e subjetividade social, expresso na produção de 'algo' considerado ao mesmo tempo 'novo' e ‘valioso', em algum campo da ação humana” (MITIJÁNS MATÍNEZ, 2012: 89). Essa compreensão assume a criatividade como "expressão da ação do indivíduo como sujeito, em espaços sociais caracterizados, entre outros aspectos, pela sua dimensão subjetiva”. De tal forma, ao agir criativamente as configurações subjetivas do sujeito constituídas em sua história de vida são atualizadas ao passo em que se dá a produção de novos sentidos subjetivos com a participação de sentidos configurados no espaço social de ação desse sujeito. Daí dizer que a criatividade não diz respeito a um processo específico definido por condições intrapsíquicas e sim a "uma 'emergência' resultante de configurações de processos subjetivos em contexto" (MITIJÁNS MATÍNEZ, 2012: 90).

Para Mitjáns Martínez (2012), a criatividade tem dupla dimensão, podendo originar produtos ou perfazer seus efeitos como modo de funcionamento da 
subjetividade, quando o sujeito assume recursos diferenciados na processualidade de sua ação sem que necessariamente incorra na emersão de produtos. A forma de aprender criativamente apresenta o entrelaçamento de ao menos quatro aspectos basilares, quais sejam: o exercício da condição de sujeito em seu caráter gerador; a produção sentidos subjetivos que favorecem a emersão de novidade alimentando a aprendizagem de forma recursiva; a atualização de configurações subjetivas destacando-se a aprendizagem como configuração; e, a integração da dimensão operacional da aprendizagem ao sistema subjetivo, portanto, como produção subjetiva integrada aos processos simbólico-emocionais.

A aprendizagem criativa ocorre em um aluno que, ao exercer sua condição de sujeito o faz dado ao caráter gerador de seu sistema psíquico, sendo capaz de se posicionar ativamente, confrontar e subverter o dado mediante sua perspectiva singular. Ele produz elaborações reflexivas, delineando ideias próprias e recriando material preexistente para além de uma compreensão inicial sobre o objeto de conhecimento. Tais características vão ao encontro da própria definição da categoria sujeito, conforme a teorização de González Rey, contudo, Mitjáns Martínez (2012) acrescenta os aspectos "subversão" e "transgressão" ao seu entendimento. Assim, deixa clara a distinção entre alunos que são ativos e reflexivos, mas voltados à compreensão e assimilação e aqueles que de fato problematizam e transcendem a lógica dominante, extrapolando o dado ao gerarem ideias próprias, representações personalizadas, fantasias, alternativas, enfim, produzindo sentidos subjetivos tendo os aspectos afetivo-emocionais como qualificadores da aprendizagem.

Importante é salientar que o domínio conceitual se faz extremamente importante também no tipo de aprendizagem criativa, entretanto, distintamente de outras formas de aprendizagem, não é concebido como finalidade do processo. É justamente pela relevância da compreensão dos conteúdos que a aprendizagem criativa abarca além da "novidade", o "valor", tendo-se em vista a pertinência das novas ideias e produções ao campo do conhecimento.

Considerando que durante a aprendizagem há a mobilização de configurações subjetivas variadas e a produção de uma gama de sentidos dada à fluidez dos fenômenos subjetivos, necessário se faz, à ótica de Mitjáns Martínez, desvelar os sentidos subjetivos dominantes, bem como aspectos de sua 
processualidade para que se avance na compreensão sobre a aprendizagem criativa. Nessa direção, a autora observa que incluídos nos sentidos subjetivos relacionados à aprendizagem criativa estão "representações da aprendizagem não dominantes, unidas a vivências emocionais que mobilizam, de forma recursiva, o próprio processo de aprender criativamente" (MITIJÁNS MATÍNEZ, 2012: 98).

Considerando os pressupostos de Mitjáns Martínez no contexto de ensino e aprendizagem musicais escolares, são suscitadas as seguintes questões: quais são as representações dos alunos sobre música e sobre seu ensino e aprendizagem? Elas são correspondentes às representações dominantes na subjetividade social ou delas discrepam? Quais as vivências emocionais associadas a tais representações, ou seja, quais são os elementos de sentidos subjetivos envolvidos no fenômeno representacional? Esses sentidos subjetivos se associam às configurações subjetivas alimentando o processo de aprender de forma criativa, ou, em outras palavras, a aprendizagem é mobilizada por sentidos subjetivos produzidos em sua própria processualidade fomentando, recursivamente, a produção de hipóteses e ideias próprias dos alunos?

Outro elemento concernente à aprendizagem criativa é a atualização de diversas configurações subjetivas, constituídas ao longo da vida dos sujeitos, as quais emergem no processo de aprendizagem qualificando-a. $\mathrm{Na}$ diversidade de configurações subjetivas, Mitjáns Martínez identifica a aprendizagem como configuração que atualiza-se junto às demais no curso do aprender, contribuindo para a produção de novidade. Participam da configuração subjetiva da aprendizagem diversos sentidos subjetivos, inclusive aqueles constituídos na relação com o outro, e que, no contexto da aprendizagem conferem uma emocionalidade peculiar ao processo, motivando o sujeito de forma singular.

Ainda em relação aos elementos que caracterizam a aprendizagem criativa está a constituição das operações do pensamento e estratégias de aprendizagem como processos subjetivos tendo a emoções, a imaginação, a fantasia em sua base. Como dito por Mitjáns Martínez (2012: 103), “a assunção por parte do sujeito de uma outra estratégia está ancorada nas configurações subjetivas que é capaz de mobilizar na situação, e nos sentidos subjetivos que produz nela. As estratégias de aprendizagem são, utilizando uma metáfora, 'a subjetividade em ação'”. 
Muito embora os fenômenos subjetivos sejam frequentemente vinculados aos processos artísticos, aspecto ressaltado por Mitjáns Martínez (2014: 68) ao lembrar que a imaginação aparece em representações dominantes como inerente à própria atividade artística, tais fenômenos nem sempre têm seu reconhecimento e valorização intencional em contextos de ensino e aprendizagem. Assim sendo, a teorização sobre as aprendizagens complexas e, especialmente, a concepção da aprendizagem criativa se apresenta como uma significativa contribuição ao ensino e aprendizagem não só dos conteúdos escolares tradicionais, como também à organização didática dos processos no campo artístico, o que inclui a Música.

\section{Questões suscitadas ao ensino e aprendizagem musicais em espaço escolar}

$\mathrm{Na}$ investigação sobre a história subjetiva de três sujeitos em sua formação musical, Souza (2015) desvela o modo como os processos de aprendizagem de Música são subjetivamente configurados por meio da produção de sentidos subjetivos que qualificam a experiência, tornando-a singular, com repercussão em outras esferas da vida dos participantes da pesquisa. Apesar de emoções emergirem durante a aprendizagem musical, o autor analisa que se integravam a outras emocionalidades vivenciadas em distintos momentos e contextos, organizando-se em configurações subjetivas mais estáveis. Dessa forma, a produção de sentidos concernentes à aprendizagem musical dos sujeitos investigados abarcou recursivamente elementos simbólicos e emocionais que não guardavam relação direta com a concretude do objeto da aprendizagem, mas que influenciavam na compreensão dos conteúdos estudados. Essas construções interpretativas levaram Souza (2015: 213, grifo do autor) ao entendimento de que falar de aprendizagem musical era o mesmo que tratar de "um sujeito psicológico concreto subjetivamente configurado naquela aprendizagem" e não tão somente tratar de um objeto do conhecimento.

Nessa direção, é possível inferir que o ensino musical nas escolas de educação básica terá seus efeitos ao se constituir espaço de expressão e produção de sentidos pelos sujeitos, para além da assimilação dos códigos musicais e treino de habilidades técnicas. Mas o contexto escolar pode apresentar condições limitantes ao desenvolvimento de aprendizagens complexas, voltadas ao desenvolvimento da subjetividade, tal como a aprendizagem do tipo criativa cunhada por Mitjáns Martínez 
(2012, 2014). Esses limites têm relação com o próprio status do ensino artístico na escola, que, geralmente relegado à periferia dos currículos, dispõe de carga horária extremamente reduzida para o seu desenvolvimento; de grande número de alunos por turma; de inadequados espaço físico e recursos materiais. Ademais, prática comum é a de docentes sem formação específica no campo musical atuar frente a essa linguagem, cedendo ao paradigma ultrapassado da polivalência no ensino de Arte, de modo que a consistência dos planejamentos e ações pedagógicas ficam fragilizados em decorrência dos limitados recursos dos próprios profissionais.

As condições limitantes, quando se pretende definir um espaço social de significativas relações humanas e emersão de expressões simbólico-emocionais, são desafiadoras, ainda mais tendo-se em vista que o desenvolvimento dos processos subjetivos não reduzem a importância da compreensão dos conteúdos, com o domínio conceitual e o desenvolvimento de habilidades. Como considerado por González Rey (2012b) e Mitjáns Martínez (2012), os processos operacionais se realizam como verdadeiras produções subjetivas, o que me leva a entender que carecem de tempo para a vivência e expressão do sujeito em contexto, mesmo que a subjetivação de suas experiências não se dê de forma direta e linear no espaço e tempo da aula de Música. Ainda assim, acredito ser possível e necessário viabilizar estratégias didáticas que fomentem aprendizagens complexas no referido contexto, em que o aluno seja considerado sujeito que aprende e se desenvolve por produzir sentidos subjetivos.

O pensamento de González Rey e Mitjáns Martínez provocam questões vinculadas aos processos didáticos no ensino de Música nas escolas de educação básica, tanto em termos do potencial das teorias em iluminá-los, quanto dos limites que os recursos estruturais impõem ao desenvolvimento de processos que primem pelas produções subjetivas. Dentre essas questões, então:

- Quais são os elementos de sentidos subjetivos da subjetividade social em geral, da escola e da sala de aula que se relacionam à configuração subjetiva da aprendizagem musical? Como seus efeitos impactam os alunos tendo-se em vista suas representações sobre música, sobre o ensino e aprendizagem dessa linguagem, sobre suas preferências musicais, seus comportamentos e o desenvolvimento de recursos e estratégias singulares? 
- Quais são os elementos de sentidos subjetivos constituídos na história de vida dos alunos, os quais participam da configuração subjetiva de sua aprendizagem musical?

- Como é possível interpretar os efeitos da participação dos alunos na aula de música tendo-se em vista a atualização de suas configurações subjetivas e, especialmente, da configuração subjetiva da aprendizagem musical?

- Como as atividades desenvolvidas na sala de aula podem provocar processos emocionais e simbólicos, incitando intencionalmente a emersão de sentimentos, imaginação e fantasia na vivência da linguagem musical? Quais são os efeitos de tais processos à qualidade da aprendizagem e ao desenvolvimento dos sujeitos?

- Quais os momentos de tensão, contradições e dificuldades expressos pelos sujeitos no processo de sua aprendizagem musical? Eles desencadeiam ações e estratégias singulares, acarretando a atualização das configurações subjetivas dos alunos?

- Quais são os sentidos subjetivos que estão na base da motivação dos alunos à aprendizagem musical?

- As necessidades insurgidas no contexto da aula de música se estendem a outros espaços e tempos, indicando a integração da vivência musical aos motivos/configurações subjetivas da personalidade?

- Como se dão as relações entre os diversos sujeitos envolvidos no processo de ensino e aprendizagem de música e de que maneira elas impactam a motivação e a aprendizagem?

- É possível desenvolver processos de aprendizagem criativa no âmbito do componente curricular Arte, nas condições ofertadas pelas escolas de educação básicas brasileiras?

$\mathrm{Na}$ abordagem teórica aqui assumida, as respostas a essas questões não serão verdades acabadas, inequívocas, mas construções interpretativas visando a geração de inteligibilidade sobre os processos da subjetividade em articulação à aprendizagem musical de alunos da educação básica e, recursivamente, a promoção de processos didáticos que interfiram no desenvolvimento integral desses sujeitos. 


\section{Considerações finais}

No cenário atual de intensificação das reflexões sobre a institucionalização do ensino musical na contemporaneidade e sobre o papel da música no desenvolvimento dos sujeitos, se faz pertinente a atenção às contribuições do campo psicológico tendose em vista a necessária estruturação curricular das escolas de educação básica e do componente artístico.

Na escola, ainda hoje, vê-se a primazia pelo desenvolvimento de dimensões cognitivas desvinculadas dos aspectos afetivo-emocionais, fomentando a transmissão de determinados conteúdos e o desenvolvimento de certas habilidades em detrimento de outras, de modo a formar indivíduos reprodutores da cultura tomada como algo externo.

A Teoria da Subjetividade e o conceito de aprendizagem criativa tomam em relevo as configurações subjetivas da personalidade dos sujeitos envolvidos no processo educacional, bem como as do espaço social onde tal processo de desenvolve, colocando em primeiro plano as dimensões simbólico-emocionais produzidas em unidade dialética na própria ação pedagógica, as quais coadunam para a constituição da subjetividade humana, superando dicotomias como cogniçãoemoção, social-individual, externo-interno.

É no sentido de iluminar os processos de elaboração didática, bem como de refletir sobre seus limites que as teorizações psicológicas de González Rey e Mitjáns Martínez, ainda pouco exploradas no âmbito da Educação Musical, são aqui apresentadas.

\section{Referências}

GONZÁLEZ REY, Fernando L. A configuração subjetiva dos processos psíquicos: avançando na compreensão da aprendizagem como produção subjetiva. In: MITJÁNS MARTINEZ, Albertina et al. (Orgs). Ensino e aprendizagem: a subjetividade em foco. Brasília: Liber livros, 2012a, p. 21-41.

. O pensamento de Vigotsky: contradições, desdobramentos e desenvolvimento. São Paulo: Hucitec, 2012b. 
. O valor heurístico da Subjetividade na investigação psicológica. In:

GONZÁLEZ REY, Fernando (Org.). Subjetividade, complexidade e pesquisa em psicologia. São Paulo: Pioneira Thomson Learning, 2005, p. 27-51.

MITJÁNS MARTÍNEZ, Albertina. Aprendizagem criativa: uma aprendizagem diferente. In: MITJÁNS MARTINEZ, Albertina; SCOZ, Beatriz Judith Lima; CASTANHO, Marisa Irene Siqueira (Orgs). Ensino e aprendizagem: a subjetividade em foco. Brasília: Liber Livro, 2012, p. 85-109.

. O lugar da imaginação na aprendizagem escolar: suas implicações para o trabalho pedagógico. In: MITJÁNS MARTINEZ, Albertina; ÁLVAREZ, Patrícia (Orgs). O sujeito que aprende: diálogo entre a psicanálise e o enfoque histórico-cultural. Brasília: Liber Livro, 2014, p. 63-97.

SOUZA, Elias Caires de. Tonalidades emocionais emergentes nas produções de sentidos subjetivos configuradoras da aprendizagem musical. 2015. 226 f. Tese (Doutorado em Educação) - Faculdade de educação/Universidade de Brasília UNB, Brasília, 2015. 